\title{
Tensile Behaviour of MWCNTs-Modified Epoxy Grout for Pipeline Repair
}

\author{
Hanis Hazirah Arifin ${ }^{1}$, Nurfarahin Zainal ${ }^{1}$, Libriati Zardasti ${ }^{1}$, Nordin Yahya ${ }^{1}$, \\ Kar Sing Lim² ${ }^{2}$ Jian Wey Lai ${ }^{3}$, and Norhazilan Md Noor ${ }^{1, *}$ \\ ${ }^{1}$ Faculty of Civil Engineering, Universiti Teknologi Malaysia, 81310 UTM Skudai, Johor, Malaysia \\ ${ }^{2}$ Faculty of Civil Engineering and Earth Resources, Universiti Malaysia Pahang, 26300 Gambang \\ Kuantan, Pahang, Malaysia \\ ${ }^{3}$ Orbiting Scientific \& Technology Sdn Bhd, 57000 Seri Petaling, Kuala Lumpur, Malaysia
}

\begin{abstract}
Infill material in the pipeline repair system works by filling the gap that is usually caused by corrosion before the fibre wrapper can be applied for pipeline recovery. In this study, nanocomposites were prepared by adding a small amount of Multi-walled carbon nanotubes (MWCNT) to an existing commercial epoxy resin grout aiming to evaluate their behaviour regarding neat epoxy grout as infill material in composite repair for steel pipeline subjected to external metal loss. The dispersion of the nanoparticles in the epoxy resin has been conducted through ultrasonic and calendaring technique. The results of modified epoxy grout were compared to neat epoxy grout to identify if the MWCNTs are advantageous to existing materials. By comparing the results, $0.5 \%$ of MWCNT filler has significantly improved the strength by almost $53.3 \%$. In addition, the results also indicate that MWCNT filler has increased the modulus of elasticity of the infill material. Furthermore, the morphologies image displayed that MWCNTs has been well merged into the matrix, and made the fracture cross section rougher through sharing the stress. Therefore, it demonstrated the intrinsic potential of the CNTs in modifying the properties of the composites.
\end{abstract}

\section{Introduction}

Currently, Fibre Reinforced Polymer (FRP) composites repair has become a preferred technique to repair damaged pipelines. It is highly suitable for structural improvements that require a fast and effective repair system due to its high strength, lightweight and resist to corrosion [1]. This repair system uses grout or putty to fill the irregularities or dents on pipe surface and cylindrical sections [2]. Lately, the world of pipeline repair industry is interested in reducing the usage of composite wrapping layer because it is expensive and difficult to handle especially for damaged pipes that are located in congested areas; thus it has a limited working area for the wrapping process. Therefore, researchers are looking for suitable ways in reducing the usage of composite wrap layer through layer minimization. As the effectiveness of composite repair system also depends on the performance of the

\footnotetext{
* Corresponding author: hhazirah2@live.utm.my
} 
grout [3]. One of the possible ways to achieve this goal is by increasing the contribution and performance of infill material as part of the repair system with modification of existing infill material.

Infill material is technically not designed to contribute to the strength of the pipeline composite repair system, but its primary function is only as an interface to transfer the load from the pipe to the wrapper. However, there is no much effort has been taken in producing new powerful infill material as it is only used for patching of the damaged area and providing a smooth bed for the composite wrap. As infill material can only be used in small quantity, the addition of additives is limited. Thus, the additives (filler) with nanoparticles size that can react effectively with the polymer in very small quantity are required. Therefore, there is an issue arises questioning whether is it possible to improve the existing infill through the addition of nanomaterial. Last few years, the use of nanomaterial in the polymer is kept developing. Nowadays, polymer nanocomposite materials are coming up with the incorporation of nanofillers like nano-clays, nanoparticles, nanotubes [4]. Numerous researchers have introduced the uses of nanomaterials like carbon nanotubes, graphene, Nano silica and much more in their study [5]-[7]. Due to its remarkable properties, carbon nanotubes (CNTs) are considered an ideal reinforcing agent for polymers and they have been widely used to enhance the properties of epoxy polymers. As infill material plays a crucial role in transferring the load from the pipe to the composite repair and increases the load resistance of the structure. It is important to characterize the mechanical properties of MWCNTs-modified epoxy grout in determining the level of contribution by CNTs towards strength improvement of infill material. Since pressurizes pipe will experience the most critical stress in hoop direction it will cause the pipe to fail in tension mode. Therefore, tensile properties are considered as most important properties to be understood. Hence, this study has been conducted to investigate the potential of nanofiller in enhancing the properties of grout, particularly in tensile mode.

\section{Materials and methods}

\subsection{Materials}

In this study, the existing commercially available pourable grout was used based on the combination of resin mainly Bisphenol A diglycidyl ether and amine hardener with a ratio of 2:1 respectively. It is generally used for filling and fixation in the structure application. The multi-walled carbon nanotubes (MWCNT) were selected as additives (filler) aimed to improve the properties and efficiency of infill material. Furthermore, the carbon nanotubes used in this research have an average diameter of approximately $12.0 \sim 15.0 \mathrm{~nm}$ and particle length of $12.0 \sim 15.0 \mu \mathrm{m}$ with $>97 \%$ of carbon purity with the appearance of black powder. Other material used in this study is acetone as a solvent to isolate the carbon nanotube particles.

\subsection{Sample preparations}

The specified composition of resin and hardener in the ratio of 2:1 was mixed together at the room temperature and the details proportions of the grouts elements are shown in Table 1. 
Table 1. The composition of the tested grouts.

\begin{tabular}{|c|c|c|c|c|}
\hline \multirow[b]{2}{*}{ Grout } & \multirow[b]{2}{*}{ Component } & \multicolumn{3}{|c|}{ Ingredients (Weight) } \\
\hline & & $\begin{array}{l}\text { epoxy } \\
\text { resin }\end{array}$ & hardener & MWCNT \\
\hline Neat epoxy & Resin with hardener & $40.0 \mathrm{~g}$ & $20.0 \mathrm{~g}$ & $0 \mathrm{~g}$ \\
\hline Modified epoxy & $\begin{array}{l}\text { Resin with hardener }+0.5 \% \text { of } \\
\text { MWCNTs }\end{array}$ & $40.0 \mathrm{~g}$ & $20.0 \mathrm{~g}$ & $0.3 \mathrm{~g}$ \\
\hline
\end{tabular}

The preparation of MWCNTs-modified epoxy grouts was carried out by using specified weight percentage of carbon nanotubes $(0.5 \%)$. The appropriate dispersion methods have been used in this study in order to fully utilize the unique features of this special material. Before the mixing process, carbon nanotubes were pre-dispersing in acetone solution using Hielscher Ultrasonic according to prepared weight percentage and were left evaporate for 24 hours at room temperature. It then followed by another dispersion using Three-roll mill (EXAKT 80E) with resin as shown in Figure 1.
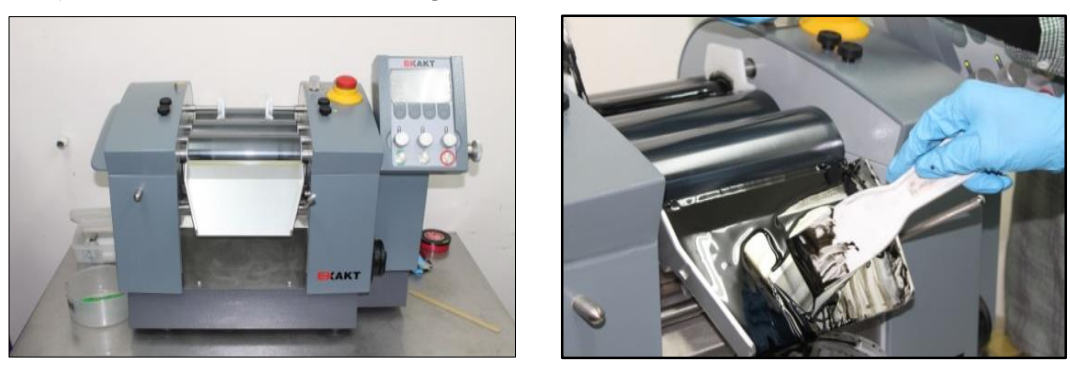

Fig. 1. Dispersion process using three-roll mill machine.

The calendaring process was applied at five consecutive times. The mixture of resin and MWCNTs was poured directly into the first roll, sheared in Gap 1 and then in Gap 2. The sheared mixture was then manually poured back into the machine for the next process. The rollers turning at a speed ratio of 9:3:1 and the time taken for each calendaring was approximately 10 minutes. The gap size between the roller and the speed (represent the lowest speed) of three-roll mill process are represented in Table 2.

Table 2. Settings of the three-roll mill for the dispersion process

\begin{tabular}{cccc}
\hline \multirow{2}{*}{ Pass number } & \multirow{2}{*}{ Rotational speed (rpm) } & \multicolumn{2}{c}{$\mathbf{0 . 5 \%}$ CNT } \\
\cline { 3 - 4 } & & Gap 1 $(\boldsymbol{\mu m})$ & Gap 2 $(\boldsymbol{\mu m})$ \\
\hline 1,2 & 350 & 90 & 30 \\
3 & 350 & 45 & 15 \\
4,5 & 350 & 15 & 5 \\
\hline
\end{tabular}

Next, an electrical mixer was used to thoroughly mix the epoxy resin with hardener at low speeds in a clean dry container until a smooth consistency specimen was achieved as shown in Figure 2. Then, the mixture was poured into the designated moulds and left for 24 hours at room temperature. 


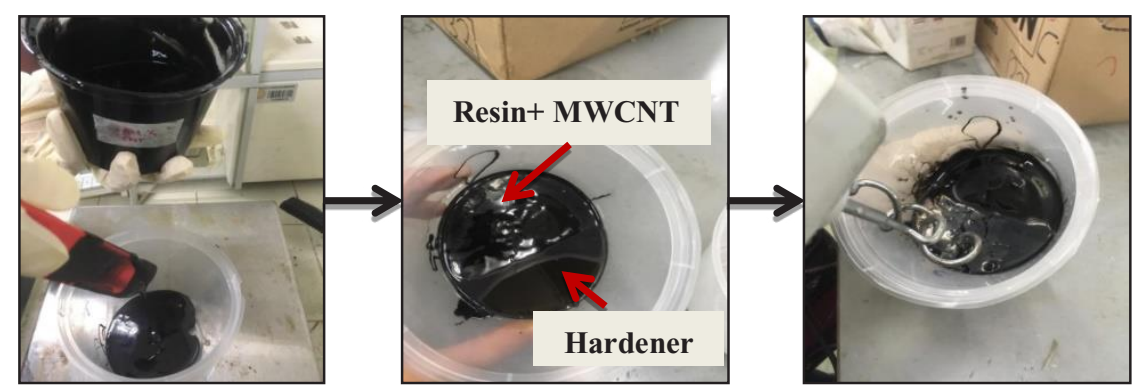

Fig. 2. Preparation of specimens.

\subsection{Tensile test}

The tensile test was performed by referring to the industry standards accordance with ASTM: D638 where five specimens are needed. Dumbell or dogbone shaped specimens were used in this testing with a typical dimension of $13.0 \mathrm{~mm} \times 3.2 \mathrm{~mm}$, that is Type I where the failure is anticipated occur at narrow section [8]. The specimen was glued with strain gauges and connected to the data logger before placed in the grips of the universal tester at a specific grip separation. Then, the specimen was pulled until failure at a crosshead speed of $5.0 \mathrm{~mm} / \mathrm{min}$ at room temperature. In order to minimize the tendency of the failure occurs out of the desired location, the end tab is suggested as an effective method for preventing premature failure at the grip length. The tests were carried out using an INSTRON 5567 Universal Testing Machine with $25 \mathrm{KN}$ of capacity. The procedure of tensile test was shown in Figure 3.
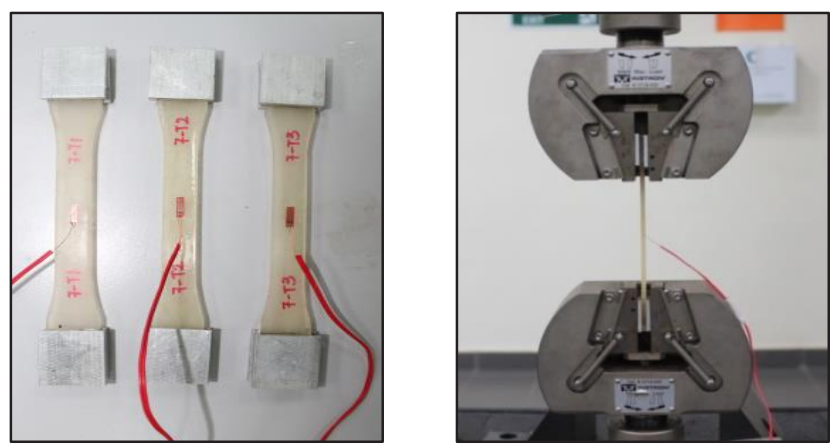

Fig. 3. Tensile testing using Instron machine.

\subsection{Field Emission Scanning Electron Microscopy (FESEM)}

The morphologies of the failure surface of epoxy grout specimens and carbon nanotubes were examined by using Field Emission Scanning Electron Microscopy (FESEM). The imaged were captured to observe the very small structures or topographic details (nanometre scale) on the surface of the entire or small part of a specimen. The FESEM analysis is essential to provide additional information on the details of the failure surface of epoxy grout. 


\section{Results and discussions}

\subsection{Tensile properties}

The summary of the average values of tensile properties for the tested grouts is given in Table 3. The tensile strength of investigated grouts are found to be $26.42 \mathrm{MPa}$ and $40.51 \mathrm{MPa}$ while the tensile modulus was recorded as $2.21 \mathrm{GPa}$ and $2.33 \mathrm{GPa}$, respectively. At ultimate stress, the strain was recorded as $0.0124 \mathrm{~mm} / \mathrm{mm}$ and $0.0187 \mathrm{~mm} / \mathrm{mm}$ for neat epoxy grout and modified epoxy grout. Based on Table 3, there is an improvement shown on the tensile strength of the modified grout. Modified epoxy grout with additional filler $(0.5 \%$ MWCNTs) showcases higher tensile strength showing a substantial increment over $53.3 \%$ than neat epoxy grout. Furthermore, there is also some improvement in the material stiffness with the addition of MWCNTs in the matrix. This indicates that the filler acts as a reinforcing agent in the polymer composite.

Figure 4 shows the typical stress curve for the tested grouts. These curves are generated from the load recorded on the Instron machine while the strain values are recorded from the data logger. As can be seen from the plotted graph, both tested grouts exhibit linear elastic stress-strain relation in the initial region up to its ultimate strength before failed and there is no plastic deformation detected. The tensile ruptures failure pattern corresponding to each tested grout is presented in Figure 5. All grouts have undergone fracture due to splitting which is perpendicular to the length of the specimen. The failure of tensile specimens occurred without noticeable deformation.

Table 3. Summary of the tensile properties.

\begin{tabular}{ccc}
\hline \multirow{2}{*}{ Properties } & \multicolumn{2}{c}{ Grouts } \\
\cline { 2 - 3 } & Neat epoxy & Modified epoxy \\
\hline Peak strength $(\mathrm{MPa})$ & $26.42 \pm 2.83$ & $40.51 \pm 5.95$ \\
Modulus $(\mathrm{GPa})$ & $2.21 \pm 0.20$ & $2.33 \pm 0.10$ \\
Strain at Failure $(\mathrm{mm} / \mathrm{mm})$ & $0.0124 \pm 0.0015$ & $0.0187 \pm 0.0040$ \\
\hline
\end{tabular}

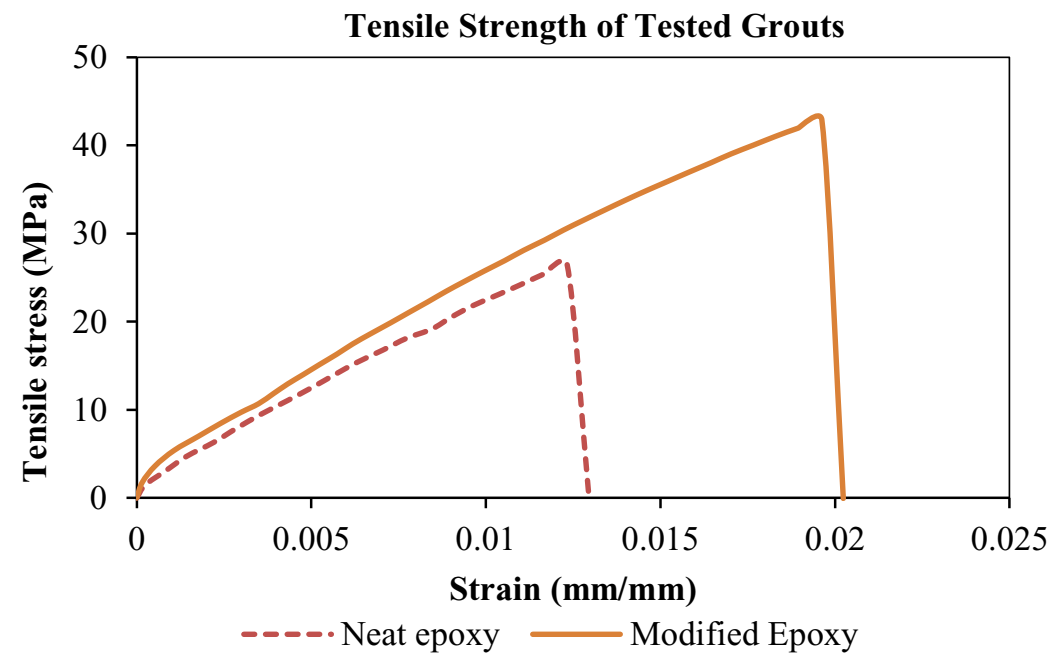

Fig. 4. Stress-strain curve of the tested grouts. 

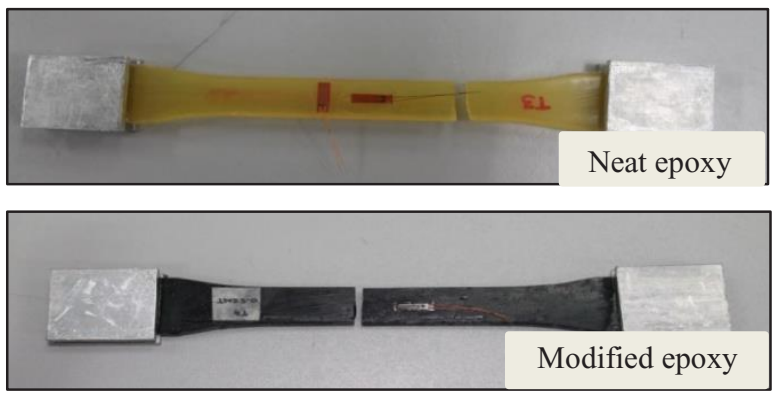

Fig. 5. Failure pattern for the tensile test.

As previously mentioned, the pressurized pipes will fail in tension mode that normally occurs in the hoop direction. Therefore, high-tensile grout is required in providing additional load bearing capacity for repaired pipe [9]; hence, a better load-sharing mechanism can be achieved in composite repair system. Mendis [10] suggest that the epoxy grout with tensile strength ranges from 28 to $43 \mathrm{MPa}$ are suitable to be used in structural rehabilitation. Based on the results, the modified epoxy grout has potential to serve as infill material in pipeline rehabilitation. The grout with a higher tensile strength provides additional requirements by sharing the hefty stress from the high operational pressure rather than just transferring it from the pipelines to the composite wrap. This condition will increase the capacity of the repaired pipe, thereby minimise the risk of failure in the pipeline by acting as a second layer protection if the composite wrap fails first.

\subsection{Morphological characterization}

The degree of dispersion of the filler inside the matrix is evaluated by morphological characterization through the Field Emission Scanning Electron Microscopy. It is well known that a uniform dispersion of the filler is a major concern, especially when using nanomaterial. Figure 6 indicates a highly entangled network of pristine MWCNTs before underwent dispersion process. Due to Van der Waals forces acting on the wide exposed surface of the nanostructures, carbon nanotubes particles tend to agglomerate. Figure 7 shows the fracture cross-sectional of FESEM images of the neat epoxy resin and the MWCNTs-modified epoxy grout. As shown in Figure 7, the fracture cross section of the neat epoxy resin shows a very smooth fracture surface but the fracture cross section of the MWCNTs-modified epoxy grout demonstrated a rough profile. From observation, the majority of MWCNTs was dispersing into the small broken segment and ranging out of the epoxy resin. These indicate the strong interfacial strength between MWCNTs and resin matrix, which prevents MWCNTs from being pulled out [11]. Thus, effectually improve the mechanical properties of modified epoxy grout. 


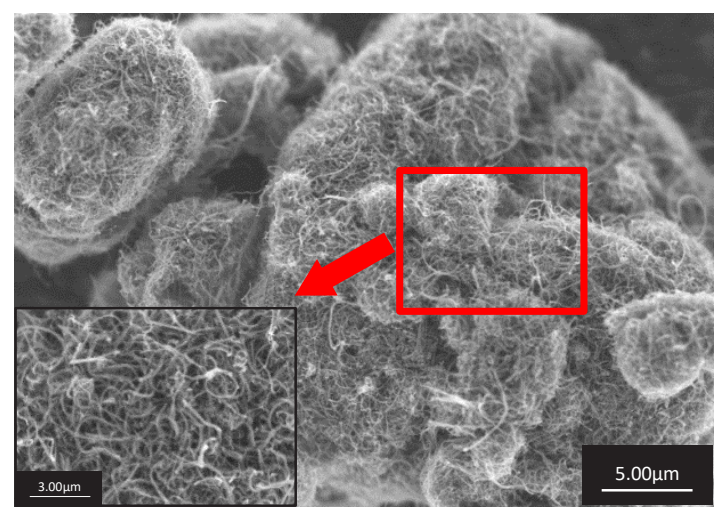

Fig. 6. FESEM imaged of Pristine MWCNTs.

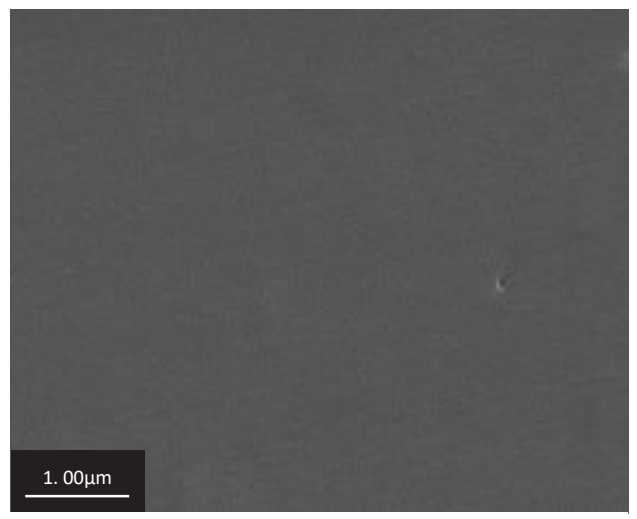

(a) Neat epoxy

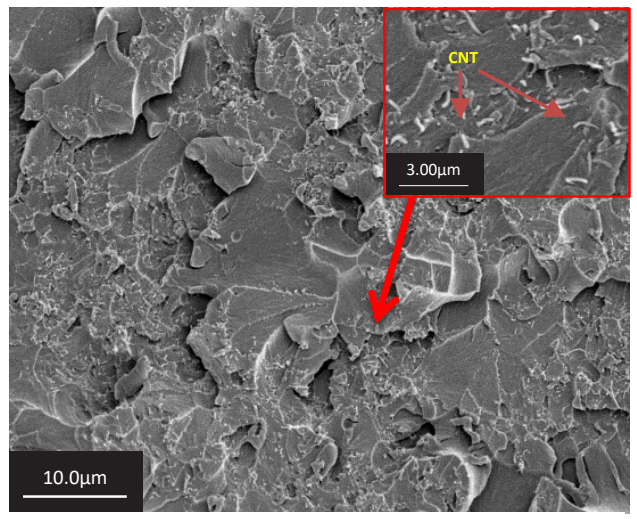

(b) Modified epoxy

Fig. 7. FESEM imaged of (a) neat epoxy grout and (b) MWCNTs-modified epoxy grout.

\section{Conclusion}

In this study, Multi-walled carbon nanotubes (MWCNTs) were introduced in the epoxy grout to enhance their mechanical properties. Generally, infill material serves as an intermediary in transferring the stresses on the internal surface of pipeline produced by internal pressure without sharing the load [5]. The image of FESEM analysis shows that MWCNTs have been well-bonded together with epoxy matrix where can effectively share the external load. It was observed that with a small inclusion of MWCNTs showed a remarkable effect on mechanical properties of infill material. The addition of $0.5 \%$ of MWCNT in epoxy gouts has enhances the tensile strength and modulus by $53.3 \%$ and $5.4 \%$, respectively. The efficiency of MWCNTs in enhancing the properties of epoxy grout is associated with the good dispersion of nanofiller in the polymer matrix. 
The work was financially supported by Universiti Teknologi Malaysia (Grant No. GUP $13 \mathrm{H} 27$ and 19H87), the Ministry of Education of Malaysia, MOE (Grant No. FRGS 4F882), Petronas Research Sdn Bhd (Grant No. CR 4C132) and some of the equipment provided by Orbiting Scientific \& Technology Sdn Bhd.

\section{References}

1. Raj, K. S. \& Nirmalkumar, K. Reliability of corroded thin walled pipes repaired with composite overwrap. Int. J. Eng. Sci. Invent. Res. Dev. I, 129-134 (2014).

2. Duell, J. M., Wilson, J. M. \& Kessler, M. R, Analysis of a carbon composite overwrap pipeline repair system. Int. J. Press. Vessel. Pip. 85, 782-788 (2008).

3. Shamsuddoha, M., Islam, M. M., Aravinthan, T., Manalo, A. \& Lau, K. Effectiveness of using fibre-reinforced polymer composites for underwater steel pipeline repairs. Compos. Struct. 100, 40-54 (2013).

4. Kumar, M. S. S., Raju, N. M. S., Sampath, P. S. \& Jayakumari, L. S. Effects of Nanomaterials on Polymer Composites - an Expatiate View. Rev. Adv. Mater. Sci. 38, 40-54 (2014).

5. Azraai, S. N. A., Lim, K. S., Yahaya, N. \& Noor, N. M. Characterization of Mechanical Properties of Graphene-Modified Epoxy Resin for Pipeline Repair. Int. J. Chem. Mol. Nucl. Mater. Metall. Eng. 10, 15-18 (2016).

6. Baltzis, D., Orfanidis, S., Lekatou, A. \& Paipetis, A. S. Stainless steel coupled with carbon nanotube-modified epoxy and carbon fibre composites: Electrochemical and mechanical study. Plast. Rubber Compos. 45, 95-105 (2016).

7. Jumahat, A., Soutis, C., Abdullah, S. A. \& Kasolang, S. Tensile Properties of Nanosilica/Epoxy Nanocomposites. Procedia Eng. 41, 1634-1640 (2012).

8. ASTM International. D638 - 10. Standard Test Method for Tensile Properties of Plastics. (American Society for Testing and Materials, 2010).

9. Azraai, S. N. A. Characterization of epoxy grout as infill material for pipeline composite repair system (Unpublished master's thesis). (Universiti Teknologi Malaysia, 2017).

10. Mendis, P. Commercial Applications and Property Requirements for Epoxies in Construction. Spec. Publ. 89, 127-140 (1985).

11. Xiao, H., Song, G., Li, H. \& Sun, L. Improved tensile properties of carbon nanotube modified epoxy and its continuous carbon fiber reinforced composites. Polym. Compos. 36, 1664-1668 (2015). 